\title{
Feynman Technique as a Heutagogical Learning Strategy for Independent and Remote Learning
}

\author{
Englevert P. Reyes ${ }^{1 *}$, Ron Mhel Francis L. Blanco ${ }^{2}$, Defanee Rose L. Doroon ${ }^{3}$, \\ Jay Lord B. Limana ${ }^{4}$, and Ana Marie A. Torcende ${ }^{5}$ \\ 1,2,3 University of San Jose-Recoletos, Cebu City, Philippines \\ 1https://orcid.org/ 0000-0002-8263-2049, 2https://orcid.org/0000-0001-7633-518X, \\ 3https://orcid.org/0000-0001-9834-0860, \\ ${ }^{4}$ Immaculate Heart of Mary Academy, Minglanilla, Cebu, Philippines, https://orcid.org/0000-0002-0411-9733 \\ ${ }^{5}$ ECC Foreign Language of the Philippines Inc., Cebu City, Philippines, https://orcid.org/0000-0003-4721-1123 \\ *Email Correspondence: englevert.reyes@usjr.edu.ph
}

\begin{abstract}
The Feynman Technique is a mental model and learning strategy used to simplify any complex information. This study endeavors to provide empirical evidence on the effectiveness of the Feynman Technique as a heutagogy-based learning strategy that fits the e-learning landscape. Utilizing true experimental research design, grades 4, 7, and 11 students from typical elementary and national high schools were randomly assigned to experimental and control groups and underwent pre-and posttests. Using two-sample and paired T-tests, results show that students under the experimental group, which applied the Feynman Technique, showed higher posttest scores and learning gains than those in the control group. Hence, this study proves that the Feynman Technique can be an effective tool to improve $K-12$ students' learning, especially now given the new learning delivery modalities.
\end{abstract}

Keywords: heutagogy, learning strategy, independent learning, remote learning, experimental research, new normal in education

\subsection{Introduction}

Across the world, schools and universities have closed down to mitigate the catastrophic impact and unprecedented health threats posed by the COVID-19 pandemic. Consequently, the education sector has to embrace an alternative mode of learning - online education. Both teachers and students have undergone a steep learning curve while transitioning from face-to-face instruction to remote teaching and learning via digital platforms. Blended and hybrid learning, flexible and modular learning, synchronous and asynchronous learning, among many other learning setups, have become the new norm in today's education. With online learning, learners are given more than ever the power to exercise autonomy and selfdetermination in the learning processes, which is the core principle of the emerging learning approach known as heutagogy (Moore, 2020).

In the Philippines, the Department of Education (DepEd) takes the herculean challenge to continue learning beyond the accustomed 
setup. As mandated in DepEd Order (DO) 12 s. 2020, schools and other community learning centers had to close their physical conduct of classes to ensure the health, safety, and well-being of learners and teachers. While DepEd was preparing for the opening of the school year 2020-2021, DepEd Sec. Leonor Briones announced that the department had put all possible learning resources, particularly the self-learning modules (SLMs), in place so that each learner will not be burdened and to ensure access to basic education despite the pandemic (DepEd, 2020). Adonis (2020) noted that at the start of classes in public schools, students might adapt to the new learning delivery modalities, but absorbing the lessons could be troublesome as students struggle to understand the contents of the modules by themselves. Wanting to assist their children but left with no choice, many parents and guardians resorted to answering the questions and activities in the modules themselves. Although DepEd strategically provides "modular, television-based, radio-based, blended, and online" instruction, still several restraining factors continue to persist (DepEd, 2020, par. 2). Along with DepEd, the Commission on Higher Education (CHED) also released its Memorandum Order No. 4, series of 2020 that stipulates the guidelines for Flexible Learning, a method of learning where students are given autonomy in how, what, when, and where they learn ("Flexible Learning Definition and Meaning," 2019).

Apart from the similar struggles in both basic and higher education levels, schools also incorporate synchronous and asynchronous learning, alongside other alternatives, to address the flooded concerns involved in the shift to the new normal in the Philippine education system. Synchronous learning happens when the learning activities and instructor's guidance are done in real-time connectivity, such as through video conferencing. On the other hand, asynchronous learning emphasizes independent learning, in the absence of a present, real-time teacher, by utilizing modules or otherwise known as learning packets (Villena \& Asano, 2020). The Learning Management System (LMS), now a household term, refers to an online portal that connects teachers and students outside the classroom to create an avenue for instructions and monitoring (Malik et al., 2017). The implementation of the LMS may be unique for each teacher and every school or academic institution.

Given the extraordinary circumstances wherein learning in an online or virtual environment is not an option anymore but a necessity, the current educational system shows a heavy leaning towards a learner-directed approach (Moore, 2020). As learning opportunities center on the use of technology, heutagogy, as an emerging net-centric learning approach, gains today's attention of educational experts across the globe. The ultimate goal of heutagogy is for learners to exhibit high autonomy and self-determination so that they become "well-prepared for the complexities of today's workplace" (Blaschke \& Hase, 2016). Tumapon (2020) asserted that teachers must provide learners with means that develop learners' self-efficacy - a trait essential to improving the learner's performance with lesser monitoring by the teacher. Teachers should expose students to other helpful learning methods and enable students to find opportunities to create their strategies (Ramos, 2015). Hence, this paper introduces a self-determined study model or technique, known as the Feynman Technique which was developed by the 1965 Nobel-prizewinning physicist Richard Feynman. The very goal of this study model is to simplify substantive and complex concepts. Richard Feynman, himself, was dubbed as "the Great Explainer" since he was known to explain exceptionally the most complex ideas in the simplest terms (Goodstein et al., 1996).

Having difficulty adapting to remote learning, learners are redirected to find relevant solutions and wise options such that they can learn on their 
own. This phenomenon explains the need to take a heutagogical approach in teaching and learning. In building self-efficacy among learners, educators should strive to enable learners to explore their problems profoundly and find solutions without the teacher's constant coaching (Blaschke \& Hase, 2016). Despite the strong potential of heutagogy to become the standard approach to learning in this new era, the challenge is the lack of empiricallystudied strategies, methods, and systems that support heutagogy due to its relative newness (Moore, 2020).

In this study, the Feynman Technique is viewed as a promising learning strategy that adheres to the principles of heutagogy. Within the process of this study model, students exhibit a significant level of independence as they ensure that their grasp on the subject contents and lessons are profound and accurate. Nevertheless, the effectiveness of the Feynman Technique as a learning strategy is still unexplored. Most of the existing studies are focused on the specific mathematical and scientific models that Richard Feynman developed and contributed in his fields of expertise (Arlego \& Fanaro, 2017; Battaglia et al., 2017; De Luca, 2012; Kontokostas \& Kalkanis, 2013; Seltzer-Kelly, 2013; Wong et al., 2014). None has attempted to examine, apply, and test empirically the effectiveness of Feynman Technique as a learning strategy.

Thus, this study endeavors to provide empirical evidence of the effectiveness of the Feynman Technique as a heutagogy-based learning strategy that fits the e-learning landscape.

\section{Conceptual Framework}

This study is anchored on the Constructivist Theory by Catherine Twomey Fosnot (1989). In her theory, she posited four major concepts: (1) learning relies on what people already know; (2) new ideas arise as people adjust and change the old ones; (3) learning includes inventing ideas rather than gathering a set of facts mechanically; and (4) substantive learning occurs by rethinking old ideas and arriving at new perspectives or paradigms after new ideas clash with old ones.

Another school of learning that supports this study is autodidacticism, also referred to as selfeducation or self-directed learning. According to Brockett and Hiemstra (1991), the learner should learn to regulate his learning and direct himself to formulate schemes in realizing his goal. With numerous technological resources available, learners are now more enabled to self-directed learning that comprises the freedom to choose the methods of inquiry, self-regulation, and reflection.

Hase and Kenyon (2013) also proposed an approach suited for a 21st-century education, the heutagogy or self-determined learning. Heutagogy delves into the learner's adaptability to various learning challenges previously neglected under the constructivist approach. Blaschke and Hase (2016) asserted that self-reflection and metacognition influence the learner's motivation to arrive at a solution based on his derived process (also known as double-loop learning). Heutagogy has become a new trend in education due to the disruptions caused by the pandemic (Moore, 2020). As an approach, it emphasizes how learning can be processed using online technology and other strategies that could help learners think more deeply about their assumptions and beliefs - clarifying and simplifying their learning experiences.

The three theories/approaches, though they hold some distinct features, become integrated into this study since they reinforce the attributes of the Feynman Technique as a student-centered and self-determined learning strategy that emphasizes ideas of processing and critical thinking. Moreover, with particular attention to heutagogy, the Feynman Technique enables a learner to discover independently a concept and choose his own best way to arrive at the desired outcome. The goal of Feynman Technique is for a learner to explain a 
complex concept in its simplest manner which allows even a child to understand. Under this technique, Feynman proposed these four basic steps: (1) writing down everything about the chosen or focused topic/concept based on prior knowledge or after receiving input, (2) explaining the topic in simple terms as if teaching a child, (3) reviewing and identifying gaps or problem areas of one's understanding or explanation, and (4) simplifying the language further or creating analogies to understand better. It can be noted that steps 2-4 are expected to be iterative or constitute a looping process. Probing further about a topic may include the use of online resources. When this rigorous process of alterations and revisions reaches exhaustion, the learner: (a) learns a new idea, (b) understands an existing idea better, (c) remembers an idea, and (d) goes beyond learning the concept through reconstruction. The Feynman Technique allows the learner to assess which aspect of his knowledge or understanding is solid and which aspect is weak. This learning procedure concretizes Albert Einstein's wisdom, "If you can't explain it simply, you don't understand it well enough."

Figure 1 shows the conceptual framework of this study - highlighting the theories being anchored on, the research participants, the research design, and the outcome to be measured to establish the effectiveness of the Feynman Technique.

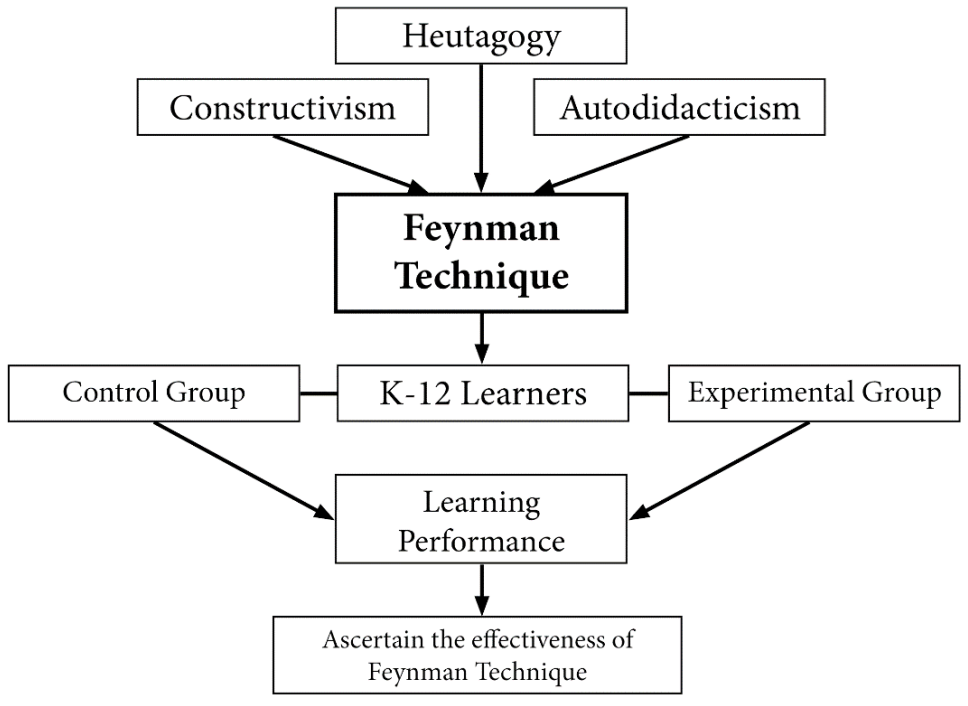

Figure 1. Conceptual Framework

\subsection{Research Design and Methods}

This study utilized true experimental research, specifically, pretest-posttest equivalent groups design. This design is also regarded as the only research procedure that can adequately establish the cause-and-effect relationship (Campbell \& Stanley, 2015). In this setup, learners were randomly assigned to two groups - experimental and control groups. During the class session, the experimental group received the treatment or the Feynman Technique while the control group experienced the standard lesson procedures indicated in DepEd's prototype daily lesson plan. Both groups were taught by the same teacher, 
at the same time and the same venue through breakout sessions. Based on the pretest results, both groups were found to be equivalent in terms of intellectual level. All these measures were done to prevent the extraneous variables from potentially influencing the outcomes of the experiment, thereby strengthening the internal validity of this research. The stages of the pretest and posttest design follow the experimental model of Campbell and Stanley (2015) as shown below:

$\begin{array}{llll}\mathrm{R} & \mathrm{O}_{1} & \mathrm{X} & \mathrm{O}_{2} \\ \mathrm{R} & \mathrm{O}_{1} & & \mathrm{O}_{2}\end{array}$

Referring to the model above, the R stands for randomized selection and assignment of individual participants, $\mathrm{O}_{1}$ for pretest, $\mathrm{O}_{2}$ for posttest, and $\mathrm{X}$ for the intervention, which was the application of the Feynman Technique.

The participants were Grades 4, 7, and 11 from a local public elementary school and a national high school. These grade levels were selected as these are the beginning levels (as stated in the K-12 curriculum of DepEd) in elementary (intermediate), junior high, and senior high school levels. Although getting all the grade levels would be ideal, the researchers' limited time and resources impeded them from doing so. Furthermore, since all participants came from the same school, their experiences in terms of school culture, practices, norms, and standards would be the same; hence, the participants were comparable. The total participants from Grade 4 were 34 with 19 females and 15 males, aged 8-11 years old. The Grade 7 level had the highest number of participants with a classroom population of 37 with 26 females and 12 males, aged 12-13. The last participants were from Grade 11, taking up Bread and Pastry Production under the TVL (Technical-Vocational-Livelihood) strand, aged 16-17, all females. Grade 11 had the least number of participants based on the attendance followed within the entire time frame of the actual testing.

After identifying the sample size, multi-stage sampling was done. Samples were taken in stages using smaller sampling units at each chapter. These chapters include stratified random sampling and simple random sampling. During the first phase, stratified random sampling was employed to identify students from one section. They were then grouped into strata and categorized as high and low proficient English learners (based on the English Proficiency Test of the Department of Education). During the second phase, simple random sampling was used. Students from each stratum were divided equally and chosen randomly to complete both the control and the experimental groups.

The lesson topics were determined by referring to the competencies stipulated in DepEd K-12 English Curriculum Guide.

Table 1. Competencies measured for pre-and posttest

\begin{tabular}{lll}
\hline $\begin{array}{l}\text { GRADE } \\
\text { LEVEL }\end{array}$ & TOPIC & COMPETENCY \\
\hline Grade 4 & $\begin{array}{l}\text { Denotation and } \\
\text { Connotation }\end{array}$ & $\begin{array}{l}\text { EN4V-IId-20.1: Denotation } \\
\text { EN4V-IId-20.2: Connotation }\end{array}$ \\
Grade 7 & Hyponyms & $\begin{array}{l}\text { EN7V-III-d-13: Determine words or expressions with } \\
\text { hyponymous relations in a selection }\end{array}$ \\
Grade 11 & $\begin{array}{l}\text { Patterns of } \\
\text { Developmental } \\
\text { Writing }\end{array}$ & $\begin{array}{l}\text { EN11/12RWS-IIlbf3: Distinguishes between and } \\
\text { among patterns of development in writing across } \\
\text { disciplines. }\end{array}$ \\
& & \\
\hline
\end{tabular}


The research tool used was a thirty-fiveitem multiple-choice test questionnaire, which underwent a dry run testing to different students but from similar schools. The test items were then statistically treated using Cronbach Alpha Statistical Measure. The results yielded 0.79 and higher Cronbach alphas, which indicate good reliability. The tests differed accordingly based on the competencies (see table 1 for the competencies). Separate consent letters had been sent to the schools for dry run testing and schools for actual testing and experimentation before the approval was granted.

The three-week study was broken down into three phases as seen in Figure 2: (a) Pretesting, (b) Intervention, and (c) Posttesting. During the Pretesting phase, English Proficiency Test and Pretest were conducted in the first week to actualize the sampling mechanisms and establish groups' equivalency. In the second phase, the intervention or treatment was implemented. The control group received the conventional teaching method while the experimental group was taught using the Feynman Technique. The process of the Feynman Technique involved the following steps: (1) a fifteen-minute reading of the given material/handout and taking notes of the concept, (2) a ten-minute self-discussion or explanation, (3) a five-minute review activity from the constructed knowledge with scaffolding, and (4) a five-minute verification of one's understanding of the concept aimed at simplifying its meaning. Researchers collected learners' actual written compositions as evidence of the treatment process. The last phase was the Posttesting, wherein both groups took a test similar to the pretest.

As a measure against validity threats, the researchers became experimenters of the study since they possessed a full grasp of the Feynman Technique and its processes. Weeks before the conduct of the experiment, the experimenters had built a rapport with the participants as the former served as student teachers or teacher assistants. This, in effect, brought in the naturalness of behaviors among all the student participants. During the study, there were also setbacks caused by factors beyond the control of the researchers. These limitations included student attendance, teacher support, and time constraints.

The data gathered from the pretest and posttest were statistically treated using paired t-test and two-sample t-test. The paired t-test is a type of parametric procedure used to compare two quantitative measurements taken from the same individuals whereas the two-sample t-test was used to compare two independent groups. Both can tell if there is a significant difference between the means of two groups or measures.

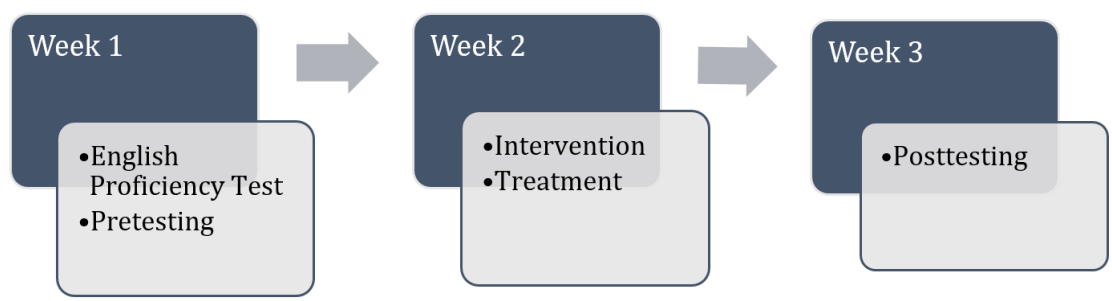

Figure 2. Time frame for the implementation of the study 


\subsection{Results and Discussion}

Data on the various variables taken during the study period underwent statistical analyses to determine the effectiveness of Feynman Technique.

One prerequisite of a parametric test like a t-test is testing the raw data for normality. All preand post-test data results of both experimental and control groups passed the normality test. Hence, t-tests (paired and two-sample) could be applied.
The distribution of scores gives us an overview that (a) during the pretest, the majority of the participants' scores fell under 'fairly satisfactory' and 'satisfactory' and (b) during posttest, a significant number improved, placing the bulk of participants under 'approaching proficiency' and a few under 'proficient' and 'satisfactory.' It can be further noted that the most apparent leaps were coming from the experimental groups.

Table 2. Distribution of participants'scores during the pre-and posttesting

\begin{tabular}{|c|c|c|c|c|c|c|c|c|c|c|c|c|c|}
\hline \multirow{3}{*}{ Scores } & \multicolumn{4}{|c|}{ Grade 4} & \multicolumn{4}{|c|}{ Grade 7} & \multicolumn{4}{|c|}{ Grade 11} & \multirow{3}{*}{ Interpretation } \\
\hline & \multicolumn{2}{|c|}{ Experimental } & \multicolumn{2}{|c|}{ Control } & \multicolumn{2}{|c|}{ Experimental } & \multicolumn{2}{|c|}{ Control } & \multicolumn{2}{|c|}{ Experimental } & \multicolumn{2}{|c|}{ Control } & \\
\hline & Pre & Post & Pre & Post & Pre & Post & Pre & Post & Pre & Post & Pre & Post & \\
\hline $28-35$ & 0 & 2 & 0 & 0 & 0 & 4 & 0 & 0 & 0 & 1 & 0 & 0 & Proficient \\
\hline $21-27$ & 3 & 8 & 1 & 5 & 8 & 15 & 8 & 12 & 3 & 8 & 3 & 3 & $\begin{array}{l}\text { Approaching } \\
\text { Proficiency }\end{array}$ \\
\hline $15-20$ & 8 & 6 & 9 & 10 & 9 & 0 & 8 & 7 & 5 & 1 & 5 & 7 & Satisfactory \\
\hline $7-14$ & 6 & 1 & 7 & 2 & 2 & 0 & 3 & 0 & 2 & 0 & 2 & 0 & Fairly Satisfactory \\
\hline $1-6$ & 0 & 0 & 0 & 0 & 0 & 0 & 0 & 0 & 0 & 0 & 0 & 0 & Poor \\
\hline
\end{tabular}

The participants were assumed to have no background about the topics or concepts introduced to them during the pretesting. Therefore, a two-sample t-test had to be applied to establish the comparability or equivalency of both groups (experimental and control) in each grade level. Table 3 indicates that the $p$ values $(p=0.528, p=$ $0.942, p=0.630$ for grades 4,7 , and 11 , respectively) were all greater than .05 , which implies that there is no significant difference between the experimental and control groups. The result confirms that the participants coming from the two different groups were deemed comparable or equivalent and are on an equal footing at the start of the experiment. Furthermore, the results strengthened the internal validity of the experiment.
Tables 4 and 5 measure the changes that occurred before and after the treatment in both control and experimental groups, respectively, across all levels. All grade levels in both groups demonstrated a significant increase in pre- and posttest scores, except for the Grade 11 participants under the control group, with $\mathrm{t}(9)=0.000, \mathrm{p}=$ 1.000. Based on actual observation, probable factors behind this lack of improvement were the lack of interest and tardiness in reporting to class. Nevertheless, the results generally imply that when students were taught about the lesson in whatever forms, ways, or strategies, learners were expected to improve. Control groups proved to gain some learning growth still despite receiving only traditional teaching methods. It is also equally 
important to pinpoint how the Feynman Technique could still significantly improve learning even if the learner was as young as eight years old. As a self-determined learning strategy, the Feynman Technique is assumed to work only for learners with high autonomy, reflection, and maturity, in which age becomes a determining factor (Piaget, 1964; Kuhn, 2000). The results proved otherwise - that the Feynman Technique showed potential applicability and benefits, not only to high school and college students but even to children at the elementary level.

Table 3. Two-sample t-test results on pretest between groups in all levels

\begin{tabular}{llllllll}
\hline Grade Level & Mean & SD & T-Value & P-Value & Df & Decision & Interpretation \\
\hline G4PretestExperimental & 15.82 & 4.10 & 0.64 & 0.528 & 30 & Accept & No Significant Difference \\
G4PretestControl & 15.00 & 3.39 & & & & & \\
G7PretestExperimental & 19.16 & 4.52 & 0.07 & 0.942 & 35 & Accept & No Significant Difference \\
G7PretestControl & 19.05 & 4.26 & & & & & \\
G11PretestExperimental & 17.40 & 5.76 & -0.49 & 0.630 & 16 & Accept & No Significant Difference \\
G11PretestControl & 18.50 & 4.12 & & & & & \\
\hline
\end{tabular}

Table 4. Paired t-test results on pre-and posttests of the control group in all levels

\begin{tabular}{llllllll}
\hline Grade Level & Mean & SD & T-Value & P-Value & Df & Decision & Interpretation \\
\hline G4Pretest & 15.00 & 3.39 & -3.24 & 0.005 & 16 & Reject & Significant Difference \\
G4Posttest & 18.47 & 4.27 & & & & & \\
G7Pretest & 19.053 & 4.262 & -2.29 & 0.034 & 18 & Reject & Significant Difference \\
G7Posttest & 21.474 & 3.339 & & & & & \\
G11Pretest & 18.50 & 4.12 & 0.000 & 1.000 & 9 & Accept & No Significant Difference \\
G11Posttest & 18.50 & 3.84 & & & & & \\
\hline
\end{tabular}

Table 5. Paired t-test results on pre-and posttests of the experimental group in all levels

\begin{tabular}{llllllll}
\hline Grade Level & Mean & SD & T-Value & P-Value & Df & Decision & Interpretation \\
\hline G4Pretest & 15.82 & 4.10 & -5.96 & 0.000 & 16 & Reject & Significant Difference \\
G4Posttest & 23.18 & 4.94 & & & & & \\
G7Pretest & 19.16 & 4.52 & -6.77 & 0.000 & 18 & Reject & Significant Difference \\
G7Posttest & 26.16 & 1.68 & & & & & \\
G11Pretest & 17.40 & 5.76 & -3.97 & 0.003 & 9 & Reject & Significant Difference \\
G11Posttest & 24.00 & 3.74 & & & & & \\
\hline
\end{tabular}


In any true experiment study, the control group mainly functions as a baseline or comparison group. The control group provides a point of reference when measuring the effect of the Feynman Technique on the students' learning. Hence, Tables 6 and 7 indicate results that compare the posttest performances and the learning gains between the experimental and the control groups. A learning gain score was obtained by subtracting an individual's pretest score from his/her posttest score (LG = Posttest - Pretest). Using a two-sample t-test in comparing the posttest and the learning gain scores of both experimental and control groups could determine if the two groups have varying leaps of improvement and whether the difference between the two is statistically significant or not. Furthermore, the groups' difference helps confirm or validate the effectiveness of the Feynman Technique as a heutagogical learning strategy. Though the previous tables (tables 4 and 5) indicate that all the participating students significantly improved during the posttest regardless of the type of intervention, Table 6 gives a more profound finding by revealing that the posttest performances of the two groups per grade level were significantly different. In all grade levels, the experimental group consistently obtained better or higher posttest scores compared to the control group with $\mathrm{t}(31)=2.97, \mathrm{p}=0.006 ; \mathrm{t}(26)=5.46, \mathrm{p}=$ $0.000 ; t(17)=3.25, p=0.005$, for grades 4,7 , and 11 , respectively. In the same manner, Table 7 shows a significant difference between the two groups in terms of their learning gains. The experimental groups had greater learning leaps as compared to the control groups with $\mathrm{t}(31)=2.38, \mathrm{p}=0.024 ; \mathrm{t}(35)$ $=3.10, \mathrm{p}=0.004 ; \mathrm{t}(13)=3.49, \mathrm{p}=0.004$, for grades 4,7 , and 11 , respectively.
The main advantage of employing a true experimental design is its effectiveness and adequacy to establish a cause-and-effect relationship (Campbell \& Stanley, 2015). This experiment has provided conclusive evidence on the effectiveness of the Feynman Technique. The consistent and better test results of students from the experimental groups were attributed to the use of Feynman Technique in this study. Participants revealed that most often, learning for them was simply regurgitating facts and information (Lord \& Baviskar, 2007). The Feynman Technique, however, seeks to dispel this low-level thinking practice by encouraging deeper learning processes, which include synthesis (putting complexideas into simple terms), analysis (identifying gaps of knowledge), evaluation (testing one's understanding), creativity (using analogies to explain better or remember the concept), and metacognition (thinking about one's own thinking) (Bloom, 1956; Piaget, 1964; Kuhn 2000). If the learner can explain an idea in simple language, then he/she has deeply understood it (Einstein, n.d.). With the Feynman Technique, learners are also encouraged to use digital tools and resources to further their understanding of the concept (Moreillon, 2015; Genova, 2019). Feynman Technique is a learning strategy that allows the learner to exercise high autonomy and selfregulation. These requisites make the Feynman Technique an effective and superior learning method, especially for 21st-century learning (Kuhlthau et al., 2015; Kereluik et al., 2013) and education in the new normal (Dziuban et al., 2018; Triyason et al., 2020). The Feynman Technique shows great potential as the primary learning strategy amid the widespread demand for online or remote learning. 
Table 6. Two-sample t-test results on posttest between groups in all levels

\begin{tabular}{llllllll}
\hline Grade Level & Mean & SD & T-Value & P-Value & Df & Decision & Interpretation \\
\hline G4PosttestExperimental & 23.18 & 4.94 & 2.97 & 0.006 & 31 & Reject & Significant Difference \\
G4PosttestControl & 18.47 & 4.27 & & & & & \\
G7PosttestExperimental & 26.16 & 1.68 & 5.46 & 0.000 & 26 & Reject & Significant Difference \\
G7PosttestControl & 21.47 & 3.34 & & & & & \\
G11PosttestExperimental & 24.00 & 3.74 & 3.25 & 0.005 & 17 & Reject & Significant Difference \\
G11PosttestControl & 18.00 & 3.84 & & & & & \\
\hline
\end{tabular}

Table 7. Two-sample t-test results of learning gains for all groups in all levels

\begin{tabular}{llllllll}
\hline Grade Level & Mean & SD & T-Value & P-Value & Df & Decision & Interpretation \\
\hline G4Experimental & 7.35 & 5.09 & 2.38 & 0.024 & 31 & Reject & Significant Difference \\
G4Control & 3.37 & 4.42 & & & & & \\
G7Experimental & 7.00 & 4.51 & 3.10 & 0.004 & 35 & Reject & Significant Difference \\
G7Control & 2.42 & 4.60 & & & & & \\
G11Experimental & 6.60 & 5.25 & 3.49 & 0.004 & 13 & Reject & Significant Difference \\
G11Control & 0.00 & 2.87 & & & & & \\
\hline
\end{tabular}

\section{0 Conclusion and Recommendation}

This study has proven the effectiveness of the Feynman Technique as a heutagogy-based learning strategy after utilizing a true experimental research design. Students (experimental group) who were exposed to the Feynman Technique exceeded their counterparts in the control group in terms of the posttest and learning gain scores. The positive results can be attributed to its constructivist, autodidactic, and heutagogical approach. Deep understanding of the concepts and demonstration of high-level autonomy and self-regulation enable the learners to learn their lesson more effectively and efficiently, especially now given the new learning delivery modalities. The Feynman Technique as a pedagogical practice reemphasizes that independent learning plays a crucial role in students' authentic learning. Using the Feynman Technique as a teaching strategy can help learners improve their academic performance and develop the necessary 21st-century skills. Adopting a pedagogy that allows complex information to be digested into simpler concepts, teachers and school administrators may be able to find an answer to the difficulty of the students to learn in a remote or modular learning setup. With the recognition of the limitations of this study, further research is recommended, which may include: [1] looking for similar strategies to elevate student performance during online and offline learning; [2] introducing the technique to learners in an actual remote learning setup; and [3] applying this method in other academic subjects, fields, and disciplines, or even in the workplace. 


\section{References}

Adonis, M. (2020). DepEd Modules Stump Even Adults. Inquirer October 08, 2020 issue. https://bit.ly/3mZe3ow

Arlego, M., \& Fanaro, M.D. (2017). Light and matter diffraction from the unified viewpoint of Feynman's Sum of all Paths. European Journal of Physics Education, 8, 16-26. https://doi. org/10.20308/ejpe.v8i2.164

Battaglia, O. R., Di Paola, B., \& Fazio, C. (2017). K-means Clustering to Study How Student Reasoning Lines Can Be Modified by a Learning Activity Based on Feynman's Unifying Approach. Eurasia Journal of Mathematics, Science and Technology Education, 13(6), 2005-2038. https://doi. org/10.12973/eurasia.2017.01211a

Blaschke, L. M., \& Hase, S. (2016). Heutagogy: A holistic framework for creating twentyfirst-century self-determined learners. In The future of ubiquitous learning (pp. 25-40). Springer, Berlin, Heidelberg. https://doi. org/10.1007/978-3-662-47724-3

Bloom, B. S. (1956). Taxonomy of educational objectives. Vol. 1: Cognitive domain. New York: McKay, 20(24), 1. https://bit.ly/3F24zT3

Brockett, R. G., and Hiemstra, R. (1991) A Conceptual Framework for Understanding Self-Direction in Adult Learning. SelfDirection in Adult Learning: Perspectives on Theory, Research, and Practice. https://doi. org/10.4324/9780429457319

Campbell, D. T., \& Stanley, J. C. (2015). Experimental and Quasi-Experimental Designs for Research. https://doi.org/10.1016/j.amj.2006.09.001
De Luca, R. (2012). Feynman's and Ohta's Models of a Josephson Junction. European Journal of Physics, 33(6), 1547. https://doi. org/10.1088/0143-0807/33/6/1547

DepEd (2020). DepEd prepares Self-Learning Modules for Education's New Normal. https:// bit.ly/2U3Jd1x

Dziuban, C., Graham, C. R., Moskal, P. D., Norberg, A., \& Sicilia, N. (2018). Blended learning: the new normal and emerging technologies. International journal of educational technology in Higher education, 15(1), 1-16. https://doi. org/10.1186/s41239-017-0087-5

Einstein, A. (n.d.) Albert Einstein Quotes. BrainyQuote. https://www.brainyquote.com/ quotes/albert_einstein_383803

Flexible Learning Definition and Meaning. (2019, September 16). Retrieved from https:// tophat.com/glossary/f/flexible-learning/

Fosnot, C. T. (1989). Enquiring Teachers, Enquiring Learners: A Constructivist Approach to Teaching.

Genova, M. M. (2019). 21st century language classroom with digital tools and resources. Industry 4.0, 4(3), 142-145. https:// stumejournals.com/journals/i4/2019/3/142

Goodstein, D. L., Feynman, R. P., \& Goodstein, J. R. (1996). Feynman's lost lecture: the motion of planets around the sun. WW Norton \& Company.

Hase, S., \& Kenyon, C. (Eds.). (2013). Self-determined Learning: Heutagogy in Action. Bloomsbury 
Academic Collections (3-6). https://doi. org/10.5040/9781472553232.ch-001

Kereluik, K., Mishra, P., Fahnoe, C., \& Terry, L. (2013). What knowledge is of most worth: Teacher knowledge for 21 st century learning. Journal of digital learning in teacher education, 29(4), 127-140. https://doi.org/10.1080/21532974.2 013.10784716

Kontokostas, G., \& Kalkanis, G. (2013). Teaching Electron-Positron-Photon Interactions with Hands-on Feynman Diagrams. The Physics Teacher, 51(4), 232-233. http://doi. org/10.1119/1.4795369

Kuhn, D. (2000). Metacognitive development. Current directions in psychological science, 9(5), 178-181. http://www.jstor.org/ stable/20182660

Kuhlthau, C. C., Maniotes, L. K., \& Caspari, A. K. (2015). Guided inquiry: Learning in the 21st century. Abc-Clio. https://bit.ly/3AZoJuQ

Lord, T., \& Baviskar, S. (2007). Moving students from information recitation to information understanding-Exploiting Bloom's Taxonomy in creating science questions. Journal of College Science Teaching, 36(5), 40. https://bit. ly/3ARCM5y

Malik, M., \& Fatima, G. (2017). E-Learning: Students' Perspectives about Asynchronous and Synchronous Resources at Higher Education Level. Bulletin of Education and Research, 39(2), 183-195. https://eric.ed.gov/?id=EJ1210223

Moore, R. L. (2020). Developing lifelong learning with heutagogy: contexts, critiques, and challenges. Distance Education, 41(3), 381401. https://doi.org/10.1080/01587919.2020. 1766949

Moreillon, J. (2015). Increasing interactivity in the online learning environment: Using digital tools to support students in socially constructed meaning-making. TechTrends, 59(3), 41-47. https://doi.org/10.1007/s11528015-0851-0

Piaget, J. (1964). Part I: Cognitive development in children: Piaget development and learning. Journal of research in science teaching, 2(3), 176-186. https://bit.ly/3ARCb3O

Ramos, A. (2015). Methods and Teaching Strategies Used by Teacher Education Faculty Members of one State University in the Philippines. Asia Pacific Journal of Multidisciplinary Research, 3(5). https://bit.ly/2JfLxic

Seltzer-Kelly, D. (2013). Feynman diagrams, problem spaces, and the Kuhnian revolution to come in teacher education. Educational Theory, 63(2), 133-150. https://doi.org/10.1111/edth.12014

Triyason, T., Tassanaviboon, A., \& Kanthamanon, P. (2020, July). Hybrid Classroom: Designing for the New Normal after COVID-19 Pandemic. In Proceedings of the 11th International Conference on Advances in Information Technology (pp. 1-8). https://doi. org/10.1145/3406601.3406635

Tumapon, T. (2020). Fostering Students' Selfefficacy in The New Normal. Manila Bulletin July 23, 2020 issue. https://bit.ly/2lbwQxV

Villena, D \& Asano, K., Jr. (2020). Flexible Learning 
Program:A Framework For Letran's Instructional

Delivery Platform. Pages 6-8. https://bit. ly/3ezJfHX

Wong, C. L., Chu, H. E., \& Yap, K. C. (2014). Developing a framework for analyzing definitions: A study of the Feynman Lectures. International Journal of Science Education, 36(15), 2481 2513. https://doi.org/10.1080/09500693.201 4.893594 